\title{
Influence of phylogenetic structure and climate gradients on geographical variation of the morphology of Mexican flycatcher forests assemblages (Aves: Tyrannidae)
}

\author{
Gala Cortés-Ramírez ${ }^{\text {Corresp., } 1,2}$, César A Ríos-Muñoz ${ }^{3}$, Adolfo G Navarro-Sigüenza ${ }^{1}$ \\ ${ }^{1}$ Museo de Zoología "Alfonso L. Herrera", Facultad de Ciencias, Universidad Nacional Autónoma de México, Mexico City, Mexico City, Mexico \\ 2 Posgrado en Ciencias Biológicas, Universidad Nacional Autónoma de México, Mexico City, Mexico City, Mexico \\ 3 Laboratorio de Arqueozoología, Instituto Nacional de Antropología e Historia, Mexico City, Mexico City, Mexico \\ Corresponding Author: Gala Cortés-Ramírez \\ Email address: g.cortes.ramirez@ciencias.unam.mx
}

Morphological variation is strongly related to variation in the ecological characteristics and evolutionary history of each taxon. To explore how geographical variation in morphology is related to different climatic gradients and phylogenetic structure, we analyzed the variation of morphological traits (body size, bill, and wing) of 64 species of tyrant flycatchers (Tyrannidae) distributed in Mexico. We measured these morphological traits in specimens from biological collections and related them to the climatic and topographic data of each collection locality. We performed the analyses separately at two levels: (1) the regional level and (2) the assemblage level, which was split into (assemblage I) lowland forests and (assemblage II) highland forests and other vegetation types. We also calculated the phylogenetic structure of flycatchers of each locality in order to explore the influence of climatic variables and the phylogenetic structure on the morphological variation of tyrant flycatchers, by means of linear mixed-effects models. We mapped the spatial variation of the relationship between morphological traits and environmental gradients, taking into account the phylogenetic structure. Important climatic variables explaining the morphological variation were those of temperature ranges (seasonality) and the results suggest that the phylogenetic clustering increases towards the highlands of Sierra Madre Oriental and Sierra Madre del Sur, and the lowlands of Balsas Depression. For the regional level, the spatial distribution of body size showed a pattern coincident with Bergmann's rule, with increasing in size from south to north. In the tropical lowland forests assemblage, body size tend to increase in seasonally dry forests (western Mexico) and decrease in the humid ones (eastern Mexico). In the assemblage of highland forests and other types of vegetation, morphological trait values increased northeast to southwest. Phylogenetic structure helped to explain the variation of morphology at the assemblage level but not at the regional level. The patterns of trait variation in the lowland and 
highland assemblages suggest that parts of morphological variation are explained both by the climatic gradients and by the lineage relatedness of communities. Overall, our results suggest that morphological variation is best explained by a varied set of variables, and that regression models representing this variation, as well as integrating phylogenetic patterns at different community levels, provide a new understanding of the mechanisms underlying the links among biodiversity, its geographical setting, and environmental change. 


\section{Influence of phylogenetic structure and climate gradients on}

\section{2 geographical variation in the morphology of Mexican}

\section{3 flycatcher forests assemblages (Aves: Tyrannidae)}

4 Gala Cortés-Ramírez ${ }^{1,2^{*}}$, César A. Ríos-Muñoz ${ }^{3}$ and Adolfo G. Navarro-Sigüenza ${ }^{1}$

5 1Museo de Zoología “Alfonso L. Herrera”, Facultad de Ciencias, Universidad Autónoma de México.

$6 \quad 2$ Posgrado en Ciencias Biológicas, Universidad Autónoma de México, Mexico City, Mexico.

7 [3aboratorio de Arqueozoología, Instituto Nacional de Antropología e Historia, Mexico City, Mexico.

8 * Corresponding author e-mail address: g.cortes.ramirez@ciencias.unam.mx

10 Corresponding Author:

11 Gala Cortés-Ramírez ${ }^{1,2}$

12 Museo de Zoología “Alfonso L. Herrera”, Facultad de Ciencias, Universidad Autónoma de México.

13 Apartado postal 70-399, 04510 México City.

14 Email address: g.cortes.ramirez@ciencias.unam.mx 


\section{Abstract}

27 Morphological variation is strongly related to variation in the ecological characteristics and 28 evolutionary history of each taxon. To explore how geographical variation in morphology is related to different climatic gradients and phylogenetic structure, we analyzed the variation of

30 morphological traits (body size, bill, and wing) of 64 species of tyrant flycatchers (Tyrannidae)

31 distributed in Mexico. We measured these morphological traits in specimens from biological

32 collections and related them to the climatic and topographic data of each collection locality. We

33 performed the analyses separately at two levels: (1) the regional level and (2) the assemblage

34 level, which was split into (assemblage I) lowland forests and (assemblage II) highland forests

35 and other vegetation types. We also calculated the phylogenetic structure of flycatchers of each

36 locality in order to explore the influence of climatic variables and the phylogenetic structure on

37 the morphological variation of tyrant flycatchers, by means of linear mixed-effects models. We

38 mapped the spatial variation of the relationship between morphological traits and environmental

39 gradients, taking into account the phylogenetic structure. Important climatic variables explaining

40 the morphological variation were those of temperature ranges (seasonality) and the results

41 suggest that the phylogenetic clustering increases towards the highlands of Sierra Madre Oriental

42 and Sierra Madre del Sur, and the lowlands of Balsas Depression. For the regional level, the

43 spatial distribution of body size showed a pattern coincident with Bergmann's rule, with

44 increasing in size from south to north. In the tropical lowland forests assemblage, body size tend

45 to increase in seasonally dry forests (western Mexico) and decrease in the humid ones (eastern

46 Mexico). In the assemblage of highland forests and other types of vegetation, morphological trait

47 values increased northeast to southwest. Phylogenetic structure helped to explain the variation of

48 morphology at the assemblage level but not at the regional level. The patterns of trait variation in 
49 the lowland and highland assemblages suggest that parts of morphological variation are

50 explained both by the climatic gradients and by the lineage relatedness of communities. Overall,

51 our results suggest that morphological variation is best explained by a varied set of variables, and

52 that regression models representing this variation, as well as integrating phylogenetic patterns at

53 different community levels, provide a new understanding of the mechanisms underlying the links

54 among biodiversity, its geographical setting, and environmental change.

55

56

57

58

59

60

61

62

63

64

65

66

67

\section{Introduction}

A long-standing goal in ecology and evolutionary biology is to understand the relationships among morphological diversity, evolutionary history, environment and geographic distribution. Environmental drivers of morphological diversity across geography have been extensively studied in many regions with different taxonomic groups, at different geographic, taxonomic and functional scales (Losos \& Miles, 1994; Cavender-Bares et al., 2009; Kluge \& Kessler, 2011; Violle et al., 2014; Jarzyna et al., 2015; Jarzyna \& Jetz, 2016; Lawing et al., 2017; Schneider et al., 2017; Seeholzer et al., 2017; Phillips et al. 2018; Mazel et al., 2018). As a result of previous studies that analyze the role of environment and geography as promoters of morphological diversity, patterns of gradual variation of traits have been detected for many groups. Climate seems to be one of the main environmental promoters of morphological variation, strongly influencing the variation of morphological traits across species and regions (e.g. James, 1970; Graves, 1991; Kivelä et al., 2011; Maestri et al., 2016; Xu et al., 2017). However, the role of climate and other environmental variables is poorly understood. Even though many studies have demonstrated its associations with morphological traits, the question remains to what extent and 
72 by which mechanisms such associations are maintained and may influence distribution patterns

73 (Violle et al., 2014). It has been suggested that several variables may act simultaneously,

74 promoting morphological variation at many taxonomic and geographic scales.

75 Morphological diversity across species is driven by several ecological and evolutionary

76 processes and is usually studied as the evolution of form and function, or ecomorphology (Losos

77 \& Miles, 1994; Ricklefs, 2012; Dehling et al. 2014; Seeholzer et al. 2017; Phillips et al. 2018).

78 Also, variation in morphological diversity within communities can have effects in structuring

79 broad-scale biogeographical patterns of species richness along climatic and geographical

80 gradients (Deutsch et al., 2008; Cicero \& Koo, 2012). Morphological variation is related to

81 ecology and reflects a response to biotic and abiotic environmental factors, and it may determine

82 species' responses to climate change (Wainwright and Reilly, 1994; Pontarotti, 2010; Cicero \&

83 Koo, 2012). Climatic variables, such as temperature and precipitation, are recognized as major

84 factors determining geographical patterns of morphological variation (Hawkins et al., 2007). For

85 instance, bill size increases with higher temperatures, supporting the hypothesis that larger bills

86 are an adaptation to release heat while minimizing evaporative water loss in hot, dry

87 environments (Greenberg et al., 2012). In this way, overall bill size may be related to

88 physiological responses to regional climates, and the season of critical thermal stress may vary

89 geographically, even on relatively small spatial scales (Campbell-Tennant, Gardner \& Kearney,

90 2015; Danner and Greenberg, 2015).

91 Other factors such as evolutionary history also have been found to determine

92 geographical gradients in species variation (Jetz \& Rahbek, 2002, Kissling et al., 2007). For

93 instance, habitat filtering is an ecological process by which species are eliminated from a

94 community because of morphological or ecological similarity with other established members of 
95 the community (Wainwright and Reilly, 1994). Under this interpretation, the variation of

96 morphological variables across communities and geography is proportional to the amount of

97 phylogenetic dissimilarity among communities (Pillar and Duarte 2010), taking into account that

98 morphology is structured by phylogeny at the species level if there is phylogenetic signal.

99 Morphological variation occurs within and across species, so the complex interaction of

100 evolutionary history and environment makes it difficult to identify the underlying causes of

101 broad scale patterns of variation (Endler, 1977; Ricklefs \& Miles, 1994; Violle et al., 2014;

102 Forister et al., 2015).

103 The recognition of the promoters of broad scale patterns of morphological variation is

104 challenging due to the differential response of organisms' traits to environmental variation and

105 geographical settings (Violle et al. 2014). This limits our ability to elucidate the causes and

106 consequences of the patterns of species' morphological diversity. For instance, the geographical

107 patterns of community structure and morphological variation in response to climatic gradients

108 has shown contrasting effects of the same environmental variables (e.g. Forister et al., 2015; van

109 de Pol et al., 2016; Lawing et al., 2017). To understand how morphological diversity arises, it is

110 necessary to explore and quantify how species' morphological traits are related to their ecology,

111 how they vary geographically along environmental gradients, consider both large and small

112 spatial scales in the same region, and account for the historical contingencies limiting the

113 distribution of species assemblages and their traits (Cavender-Bares et al., 2009). In this sense,

114 phylogenetic structure and distributional data provide the historical framework to quantify

115 ecological, geographical and evolutionary patterns, in order to infer the processes that established

116 them (Saito et al. 2016; Sobral \& Cianciaruso 2016, Phillips 2018). Also, quantifying the

117 geographical distribution of morphological variation may help disentangle trade-offs found in the 
118 relationship between morphology and environmental and phylogenetic variables. Then, analyses

119 of the distribution of morphological variation are necessary for improving regional and global

120 predictions of morphological and functional change (Diniz-Filho, 2004; Rodríguez \& Ojeda,

121 2014).

122 To evaluate broad scale patterns of morphological variation and the underlying processes

123 which promote them, it is necessary to quantify the distribution of morphological traits in

124 relation to the ecology of related functional groups of species. In that sense, some authors have

125 found that the global patterns of functional richness are associated with environmental variables

126 (Kissling et al., 2009; Brum et al., 2012). To describe how morphology varies geographically

127 with environment, we explored the spatial distribution of a set of morphological variables in

128 relation to climatic gradients of the assemblages of species present in Mexico of a mainly

129 insectivorous monophyletic clade of birds, the tyrant flycatchers (Tyrannidae, sensu Tello et al.

130 2009). This taxon also belongs to a functional group of bird species that use insects and

131 arthropods as their main food resource (Hespenheide 1971; Sherry 1984). The family includes

132 more than 400 species distributed across the Americas (IOU, 2018) occurring in almost every

133 habitat. They are adapted to different elevations and occupy all vertical forest strata (Fitzpatrick

134 et al., 2004, Ridgely and Tudor, 2009). We chose the Tyrannidae of Mexico as a model system

135 because: (1) they are widely distributed in the country (Ridgely et al., 2005; Berlanga et al.,

136 2008); (2) the natural history, phylogenetic structure, and functional significance of their

137 morphological traits is relatively well known (Ohlson, Fjeldså \& Ericson, 2008; Tello et al.,

138 2009); (3) their morphology can be related to their ecology (e. g., Fitzpatrick 1980, 1981, 1985);

139 and (4) their morphology varies across environmental and geographical gradients (Brum et al., 140 2012). 
141 Our main goal was to investigate the variation of morphology across geography and to

142 determine the relationship of environmental climatic gradients as explanatory factors of

143 morphological function-related traits. We have considered the phylogenetic structure of Mexican

144 flycatchers as a factor that may help to explain how broad scale patterns in species variation are

145 established and how historical contingencies influence the response of morphological variation

146 to the environment. Our specific objectives were to test (1) whether climate conditions

147 (temperature, precipitation, and their seasonality), are associated with the observed variation in

148 morphology across tyrant flycatchers assemblages; (2) the influence of the phylogenetic structure

149 of assemblages on the geographic distribution of morphological variation and its response to

150 climate; and (3) to map the spatial distribution of morphological variation along climatic

151 gradients. Because traits are related to the ecology of the organism, for instance foraging

152 behavior or habitat use (Fitzpatrick, 1985), morphological variation is expected to reflect

153 species' responses to environmental gradients. Then, the approach we used takes into account

154 varied ranges in climate and seasonality within a lineage, abiotic variables influencing the

155 geographic distribution of species, and the phylogenetic relationships among the tyrant

156 flycatchers. Taking into account phylogenetic relationships within a community by accounting

157 for phylogenetic structuring may help to understand the influence of the composition of a

158 community on the response of traits to environmental variation (Bonetti \& Wiens, 2014; Maestri

159 et al., 2016).

160

\section{Hypothesis and assumptions}

162 Given that climatic gradients and phylogenetic structure of an area potentially play a role as

163 promoters or constrainers of morphological variation, and because this role may vary in strength 
164 and direction, we analyzed the morphological data by constructing regression models in order to

165 explain the relationship between morphology, environment and phylogenetic structure. We

166 hypothesized that, once historical and geographic factors are accounted for: Hypothesis 1)

167 climate gradients explain morphological change across geography; and hypothesis 2)

168 phylogenetic structure of a community influence morphological variation of the co-occurring

169 species. To support hypothesis 1, morphology will show clinal variation related to one or more

170 climatic variables, and a latitudinal pattern when the model is translated into a map. Conversely,

171 latitudinal variation in morphology is likely to be affected by the phylogenetic composition of

172 the area, that is, the variation of morphological traits across geography is expected to be

173 proportional to the amount of phylogenetic dissimilarity among communities (Duarte, 2011).

174 Phylogenetically clustered areas are expected to show different patterns of morphological

175 variation than areas that are phylogenetically overdispersed. Because of the tendency of species

176 to remain in an environmental space similar to that of their ancestors (Wiens \& Graham, 2005)

177 we expect that morphological variation within assemblages will be constrained. Phylogenetically

178 clustered assemblages are more likely to be restricted in their climatic ranges, whereas

179 phylogenetically overdispersed assemblages are more likely to be found in the transition zones

180 where there is a high species turnover (Graham et al., 2009). To support hypothesis 2, we would

181 expect that morphological change cannot solely be explained by climatic variables, but that

182 phylogenetic structure is also significantly associated to variation in morphology. Phylogenetic

183 structure alone is also unlikely to explain the variation of morphology; instead it is expected to

184 influence morphology along with climatic variables, meaning that the response of the trait could

185 be driven by either environmental filtering (species are filtered from a community due to 
186 morphological or ecological similarity with other co-occurring species), other biotic interactions

187 (e.g. competition), or random factors (Cavender-Bares et al., 2009; Lawing et al., 2017).

\section{METHODS}

\section{Morphological traits data and data treatment}

191 Morphological data. In order to construct regression models of environmentally-related

192 morphological variation, the morphological traits were associated to locality-specific climate,

193 topographic and phylogenetic structure data. We obtained morphological data from a sample of

194296 skin specimens from 60 species of Tyrannidae distributed in Mexico (Table S1). We

195 measured five traits (Claramunt, 2010, following recommendations by Eck et al., 2011): body

196 size (using mass data as a proxy), bill length, bill width, and bill depth (the last two taken at the

197 anterior border of the nostrils), and wing chord (wing length from the carpal joint to the tip of the

198 longest primary feather without flattening the wing). We selected these traits because they have

199 been associated use of environmental space in birds (Miles \& Ricklefs, 1984). Size is a

200 significant attribute at all levels of organization, as it predicts and explains the variation of many

201 organismal and species traits, from the proportion of parts to metabolic rates to the distribution

202 patterns (Schmidt-Nielsen, 1975; Brown, 1995; Diniz-Filho, 2004; Bonner, 2011). Bill size can

203 be positively correlated with temperature in avian taxa (Allen's rule), and the common

204 explanation for this pattern is that larger surface area of the appendage functions to dissipate

205 excess heat in warm climates and small area to retain heat in cold climates (Symonds \&

206 Tattersall, 2010; Greenberg, 2012). The bill is also the functional trait by which birds obtain

207 food, so it can be related to habitat and ecomorphological variation (Mazer \& Wheelwright,

208 1993; Jones; 2012). The relative variation of bill measures represents its variation in size and 
209 shape. Finally, wing chord plays a role in determining the aerodynamics and mechanical aspects

210 of the avian wing, thus it interacts with the effective exploitation of habitat; so it is strongly

211 related with ecology and behavior (Hamilton, 1961; Lockwood, 1998, Swaddle \& Lockwood,

212 1998, Gatesy \& Dial; 1996). Together, body size, bill size and wing chord represent

213 morphological traits that are related to the flycatcher ecology.

214 In general, we only measured adult male specimens to homogenize the data set and to

215 avoid morphological variations associated with sexual dimorphism. In some cases, we had to

216 measure female specimens ( $\sim 8 \%$ specimens) to complete the sample, and used these data based

217 on a previous test (Cortés-Ramírez, Ríos-Muñoz \& Navarro-Sigüenza, 2012) that showed that

218 the variation between sexes is smaller than interspecific variation (sensu Claramunt, 2010). We

219 took all the measurements with digital or analog Mitutoyo calipers, with a precision of $0.01 \mathrm{~mm}$.

220 For statistical analysis we used natural log-transformed measures in order to normalize the

221 dataset, and because all morphological measurements may scale with overall body size, we made

222 bill and wing size measurements relative to body size by dividing each measurement by body

223 mass. Relative variation of the three bill measurements was obtained by performing a principal

224 component analysis (PCA) to reduce the dimensionality of bill variation (Table S2), retaining the

225 first principal component as representative of bill variation and size. The first principal

226 component represented $86 \%$ of bill variation and overall size of the bill. Each morphological

227 variable was evaluated independently from the other variables.

228

229 Environmental and geographic data.

230 Climatic variables. We considered the geographic location of each specimen to obtain locality-

231 specific climate data based on a set of 19 bioclimatic variables (Hijmans et al., 2005). To reduce 
232 the dimensionality without eliminating bioclimatic variables, we constructed four climatic

233 indexes by applying a PCA on climatic variables following Alvarado-Cárdenas et al. (2013,

234 Table 1). These four indexes represent annual temperature variation, temperature range or

235 seasonality, variation of precipitation in the most humid season, and variation of precipitation in

236 the driest season. We decided to use the first principal component of each climatic index, as they

237 account for most of the climatic variation in the study area (Table S3). For each specimen we

238 extracted locality-specific climate index data using a geographic information system. We used

239 the climatic index data for each individual as a fixed explanatory variable in the regression

240 models.

242 Topographic variables. In order to separate the effects of the geographical setting, we used the

243 USGS Digital Elevation Model (altitude, USGS, 2015, https://lta.cr.usgs.gov/GTOPO30) and

244 aspect as predictor variables in all regression models. To facilitate the use of aspect as a variable

245 that describes topographic orientation, we transformed it using the cosine to express northness

246 and the sine for eastness following Kobelkowsky-Vidrio, Ríos-Muñoz, \& Navarro-Sigüenza

247 (2014).

248

\section{Historical distribution and relatedness data}

250

Assemblages of the tyrant flycatchers. In order to discriminate the effects of the evolutionary and

historical distribution of the tyrant flycatchers, we divided the data into three separate sets taking

252 into account characteristics of three constructed assemblages of tyrant flycatchers distributed

253 across Mexico. We defined an assemblage as a temporal and spatial arrangement in which

254 species potentially occur and interact; i.e., the pool of species in a geographic area (Halffter \& 
255 Moreno, 2005, Lessard et al., 2016). We defined two assemblages on the basis of environmental

256 factors delimited by elevation and vegetation type (Fig. 1, Table S1), assemblage I of the

257 lowland forests (species distributed only below $1500 \mathrm{~m}$ ) and assemblage II of the highland

258 forests (species present mainly above 1500 masl) and other types of vegetation, and the Regional

259 level (species distributed in both assemblages, which represent the species distributed in all

260 Mexico). We assigned the species to each assemblage and carried out statistical analysis

261 independently for each data set. We focused on the assemblage I data because Mexican lowland

262 forests are characterized by high levels of species richness, endemism, and habitat specialization,

263 and patterns of biogeographic distribution define them as areas with a particular evolutionary

264 history (Ríos-Muñoz \& Navarro-Sigüenza, 2012; Olguín-Monroy et al., 2013). The assemblage

265 II and the Regional level datasets were used to contrast the response of morphological variation

266 to environmental gradients at different spatial scales and community levels. It is known that the

267 influence of different variables on the morphological variation change at different scales of

268 analysis (Lawing et al., 2017).

269

270 Phylogenetic signal and phylogenetic structure. We reconstructed a phylogenetic tree for the

271 species of Tyrannidae distributed in Mexico using Jetz et al.'s (2012) bird tree with the Hackett

272 et al. (2008) backbone (Fig. S1), in order to calculate the phylogenetic signal of traits and the

273 phylogenetic structure of the localities. The phylogenetic signal was calculated for each

274 morphological variable using the generalized K statistics (Adams, 2014). Phylogenetic signal

275 indicates the tendency of related species to resemble each other more than species drawn at

276 random from the same tree (Blomberg \& Garland, 2002). Generalized K statistics tests a null

277 model of evolution of a trait by Brownian motion (drawn at random from the tree), $\mathrm{K}=1$ 
278 indicates that trait evolution is consistent with Brownian motion model, while $\mathrm{K}<1$ indicates less

279 similarity in the trait than expected under Brownian motion model, and $\mathrm{K}>1$ indicates greater

280 similarity in the trait than expected under Brownian motion model (Blomberg et al., 2003).

281 Phylogenetic signal tests were conducted using the geomorph package (Adams \& Otarola-

282 Castillo, 2013) in R version 3.4.1 (R Core Team, 2017).

283 To determine if the species in a particular area were more closely related than expected

284 by chance, we measured the phylogenetic structure of the Tyrannidae distributed at each locality.

285 To calculate the metric, we used the Net Relatedness Index (NRI, Webb et al., 2002) in the R-

286 package PhyloMeasures (Tsirogiannis \& Sandel, 2016). Values of NRI greater than zero indicate

287 phylogenetic clustering and values lower than zero indicate phylogenetic evenness or

288 overdispersion. Phylogenetic clustering is found when the co-occurring species of an area are

289 more closely related than expected by chance. Phylogenetic evenness or overdispersion is found

290 when the coexisting species of an area are less related than expected by chance (Webb et al.,

291 2002). To calculate the NRI for each locality, we used the reconstructed phylogenetic hypothesis

292 and we established which species likely co-occur by extracting presence data from distributional

293 hypotheses for Mexican Tyrannidae, generated elsewhere using ecological niche models

294 (Navarro-Sigüenza et al., Dataset S2).

295

296 Statistical analyses

297 The regression models

298 We evaluated the effects of environmental gradients and phylogenetic structure on

299 morphological variation in the tyrant flycatchers of Mexico using regression models. We

300 constructed trait maps (see below) and obtained our inferences based on the fitting of linear 
301 mixed-effects models predicting morphological variation in body size, bill and wing length. We

302 used linear mixed-effects modeling because our data are nested in the sense that samples derive

303 from multiple species, and from each species we have various specimens.

304 To find the best fitting models for each morphological variable (and assemblage dataset),

305 we followed the protocol recommended by Zuur et al. (2009). In the first step, we started with a

306 model for each morphological variable that contained all the predictor variables and their

307 interaction in the fixed part of the model. There are seven fixed predictor variables (temperature

308 variation index, temperature range or seasonality index, variation of precipitation in humid

309 season, variation of precipitation in the dry season, topographic setting, altitude, and

310 phylogenetic relatedness) and four interactions (relationships between altitude and the

311 temperature and precipitation indexes, Table 2, Table S4 model 1). After obtaining the more

312 complex linear model, we made a new model allowing random intercepts for the nested structure

313 of individuals of a species within a subfamily (Table 2, Table S4 model 2). The random intercept

314 implies that the basal value of the response is influenced by the nested structure of the data, so

315 measures within a species are more likely to be correlated just because they belong to the same

316 phylogenetic group (Militino et al., 2010). Next, we allowed random slopes and intercepts for

317 individuals of a species within a subfamily (random intercept), influenced by the phylogenetic

318 relatedness of the communities (random slope, Table 2, Table S4 model 3). Letting the slope to

319 change implies that morphological traits can change between communities in function of how

320 closely related are the species distributed on it. Then, we included the optimal variance structure

321 to the optimal model for the random terms (Table 2, Table S4 model 4). We considered that

322 different variance exist for the observations that have distinct phylogenetic membership. Next,

323 we selected the best fitting model structure for the fixed terms by sequentially adding each 
324 predictor variable and their interactions (Table 2) to the optimal random and variance structure

325 model (Table S4 models 5-16). We tested if phylogenetic relatedness influenced morphological

326 variation (Evidence for hypothesis 2, Table S4 model 12) by including it to the best fitting model

327 for the fixed terms. Finally, we included the interaction term between phylogenetic relatedness

328 and the climatic variables that best explained the morphological variation (temperature

329 seasonality, model 17). The interaction between phylogenetic relatedness and temperature

330 seasonality implies that phylogenetic structure modifies the effect of temperature seasonality on

331 the morphological variation within assemblages. The final products of the procedure described

332 were nine best fitting models predicting each morphological variable, at each assemblage, in

333 relation to climatic variables, phylogenetic structure and phylogenetic membership (Table S4,

334 Table 3). We considered the best-fitting model for each variable the one with the highest

335 maximum likelihood (ML), the Akaike information criterion (AIC), and Bayesian informative

336 criterion (BIC, Burnham \& Anderson, 2002). We performed all statistical analyses using the

337 nlme (Pinheiro et al., 2013) package in R version 3.4.1 (R Core Team, 2017).

338

\section{Mapping the spatial variation of morphological traits}

340 To map the spatial variation of the morphological traits, we extrapolated the best-fitting models

341 into GIS layers. First, we extracted the value of the predictor climatic variable in each pixel (30

342 seconds resolution) of Mexico within each assemblage. Then, we translated the best-fitting

343 model formula for the climatic index value at each pixel. For instance, if the model was: "Size

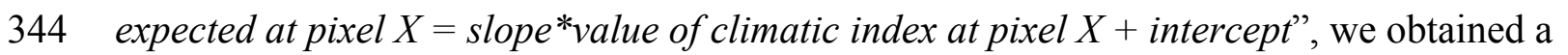

345 different value for the morphological variable at each pixel according to the model and the

346 variation of the predictor variable, generating a map of the measurements of the functional traits

347 (Moles et al., 2011). We performed all analyses using the Maptools (Lewin et al., 2011) package 
348 in $\mathrm{R}$ version 3.4.1 (R Core Team, 2017). Trait maps were visualized using ArcGIS 10 (ESRI,

349 2011).

350

351 RESULTS

352 Relationship between climatic gradients and morphological variation

353 Climatic gradients were positively associated with morphological variation of the three measured

354 traits in all three assemblages (Table 3). All best fitting models included at least one climate

355 variable among the fixed terms, specifically, temperature seasonality (temperature range).

356 Temperature appeared to explain variation in morphology at all levels analyzed. At the regional

357 level, for body size, bill and wing length, temperature was related positively and significantly to

358 morphological change, which reflects an increase in the morphological variable values as

359 temperature seasonality increases. The magnitude of the response was higher for body and bill

360 sizes (slopes 0.42 and 0.65 , respectively), whereas for wing length was close to zero (slope $=$

361 0.091. In other words, wing length does not increase as much as body and bill size with

362 increasing climatic seasonality

363 For assemblages I and II, the relationship between morphological variables and

364 temperature seasonality was also positive but not significant for some variables. For instance, the

365 regression models for bill size and temperature seasonality, and wing length and temperature

366 seasonality, for assemblage II (highland forests and other types of vegetation) there is no

367 significant relationship between both variables. For assemblage I (lowland forests), the

368 relationship between wing length and temperature sesasonality was not significant either. Only

369 the relationship between body size and temperature seasonality was significantly positive in all

370 assemblages. The relationship between bill variation and temperature seasonality was significant 
371 in assemblage I, but the magnitude of the response was less steep than in the assemblage I and

372 the regional level (slope $=0.43$ ).

373

374 Influence of phylogenetic structure on morphological variation

375 Linear mixed-effects model results indicate that phylogenetic relatedness also helped to explain

376 morphological variation in assemblages I and II, for body size, bill and wing variables (Table 3).

377 In assemblage II (highland forests and other types of vegetation), models for bill and wing were

378 not significant, whereas the model for body size was significant and positively related to

379 phylogenetic relatedness (slope $=0.60$ ). A positive correlation between body size and

380 phylogenetic relatedness means that body size values increase in areas where species that are

381 more closely related co-occur (phylogenetic clustering), and decreases in areas where species

382 that are less closely related co-occur (phylogenetic overdispersion). For assemblage I (lowland

383 forests), phylogenetic relatedness was positively correlated with bill variation, and negatively

384 with body size. The relationship between wing and phylogenetic relatedness was not significant.

385 The results indicate that there is a tendency of decreasing body size when communities become

386 more phylogenetically clustered.

387 Our results indicate that phylogenetic structure exhibits a geographical pattern (Fig. 2).

388 Both assemblages, I and II, comprised areas with phylogenetic overdispersion and phylogenetic

389 clustering (Table S5). Areas of higher phylogenetic clustering appeared to be distributed along

390 the lowland areas of the Balsas Depression, and the highlands of Sierra Madre del Sur (mountain

391 range in the southern Mexico) and Sierra Madre Oriental (mountain range in eastern Mexico).

392 Areas with high phylogenetic overdispersion are mainly distributed in southeastern Mexico (i.e.

393 southeastern Yucatan Peninsula, Tehuantepec Isthmus). 
We also measured the phylogenetic signal of the morphological traits, which returned

395 values of $\mathrm{K}=0.85$ for body size, $\mathrm{K}=0.88$ for bill variation, and $\mathrm{K}=0.87$ for wing length. All

396 values were statistically significant at $\alpha=0.05$. These values indicate that although the

397 phylogenetic signal for each morphological variable at the species level is lower than 1, values

398 are close to a Brownian motion model, which means that they are slightly less similar than

399 expected due to phylogenetic relatedness.

400

401

\section{Spatial variation of morphological traits in relation to environmental gradients}

402 Overall, trait variation was explained by temperature gradients and phylogenetic structure at assemblages other than the regional level. Mapping the predictions of the best fitting models

(Table 3) yielded different patterns of spatial distribution for morphological variation (Figures 3-

5), across the geography at different scales. Maps represent the gradient of change of the morphological traits with respect to the environmental variable that better explain their variation than other variable. We only mapped the statistically significant models. At the regional level (Fig. 3), for the three morphological variables, morphological trait values increased with increasing latitude. Phylogenetic relatedness does not help to explain morphological variation in the regional level. Assemblage I showed a morphological trait variation from northeast to

411 southwest (Fig. 4), in which body size and bill size increases towards the southwest. In the

412 lowland forests assemblage, bill size increases with increasing phylogenetic relatedness.

413 Conversely, body size increases in areas with low phylogenetic relatedness (overdispersion) and

414 decreases in areas with phylogenetic clustering (Fig. 2A). Geographically this means that

415 phylogenetic relatedness decreases body size in areas where temperature gradients predict an

416 increase in body size, and it increases in body size where temperature gradients predict a 
417 decrease. For assemblage II (Fig. 5), we mapped body size and bill variation, which are

418 explained by temperature seasonality. Increases in body size and bill variation were predicted in

419 areas of higher phylogenetic clustering and in southwestern Mexico (Fig. 2B).

420

421 DISCUSSION

422

Our results suggest that both climatic variables and phylogenetic structure influence the

morphological variation of Mexican tyrants, but the influence of the phylogenetic structure

424

varies between different assemblages and morphological traits. When we focused on how

425 climatic gradients explain the variation in morphology, our results suggest that temperature

426

seasonality is the most influential climatic variable, but the magnitude of the influence varies

427

across different assemblages. This variable assumedly represents tolerance limits of species to

428

variation in temperature, likely influencing morphological variation through maintaining habitat

use through time (Wiens \& Graham, 2005). Our results showed a latitudinal pattern that is

430

consistent with Bergmann's rule for birds: as temperature increases, body mass is likely to

431

decrease (McNab, 1971). This is a common finding in many studies, because the total surface

432

area of an animal is a proxy for heat dissipation, and predicts that a larger size can be reached in

colder climates than in warmer ones, which is linked to the temperature economy of the animal

434 (Salewski and Watt, 2017). Due to the distribution of temperature at the regional level, the

latitudinal pattern is likely to show an increase in body size from south to north (Fig. 3), but some studies found exceptions in different regions (e.g. James, 1970).

For assemblages I and II, morphological variation in western Mexico showed a pattern in

which the tendency to increase in body size was predicted in direction to both highlands and

439 lowlands of western Mexico (Fig. 4 and Fig. 5), which also contain the areas with the highest 
440 values of phylogenetic relatedness. A larger body size in less vegetated or highly seasonal areas

441 may be an adaptation to live in these types of isolated environments, and higher phylogenetic

442 relatedness agrees with the fact that western areas have been identified as a complex

443 biogeographical and ecological setting in which a highly endemic and phylogeographically

444 structured bird fauna occurs (e.g. García-Trejo \& Navarro-Sigüenza, 2004; Navarro-Sigüenza et

445 al., 2004; Ríos-Muñoz \& Navarro-Sigüenza, 2012; Arbeláez-Cortés et al., 2014). For patterns of

446 morphological variation in the eastern lowlands, like the phylogenetically overdispersed Yucatan

447 Peninsula or the Tehuantepec Isthmus, relatively constant (i.e., less seasonal) temperatures in the

448 east may have influenced the distribution of lineages and the variation of their morphological

449 traits, and consequently the particular phylogenetic community structure in those regions (Martin 450 et al., 2018).

451 The results of several studies support the idea that environmental gradients influence the

452 phylogenetic structure of the communities and therefore, phylogenetic clustering increases with 453 decreasing temperature, meaning that closely related species tend to have a strong phylogenetic 454 signal, and more similar traits and geographic distributions than expected by chance (Helmus et 455 al., 2007; Donoghue, 2008; Graham et al., 2009; Flynn et al., 2011; Tedersoo et al., 2012; Miller 456 et al., 2013). For instance, Miller et al. (2013) found that the tendency of species to remain in an 457 environmental space similar to that of their ancestors (niche conservatism, Wiens \& Graham, 458 2005) constrains honeyeater assemblages in arid regions, along a gradient of decreasing 459 precipitation. Instead, we found that tyrant's assemblages became more phylogenetically 460 clustered along a gradient of increasing temperature seasonality, but with low phylogenetic 461 signal. Our findings might reflect that variation in morphological traits of phylogenetically 462 clustered assemblages is more restricted in their climatic ranges. Moreover, on another study, 
463 Graham et al. (2009) found that hummingbird communities of the Andean region tend to be

464 phylogenetically clustered at higher elevations and colder areas, and to be overdispersed at lower

465 elevations, whereas in the transition zone between lowlands and highlands there is a species

466 turnover of relatively distant related species that can be associated to the environmental gradient.

467 We found similar results in which phylogenetically clustered communities are found in the

468 western areas (Fig. 2) which includes mountainous ranges above 1500 masl (southern Sierra

469 Madre Oriental, and the Sierra Madre del Sur), although lowland areas like the Balsas

470 Depression also show high values of phylogenetic clustering.

471 Phylogenetic clustering at higher elevations supports the idea of environmental filtering,

472 a pattern where similar traits are selected above other variations because they have an advantage

473 within the community and the environment, also allowing the coexistence of close relatives

474 (Webb et al., 2002). Phylogenetic clustering in lowlands like the Balsas Depression supports the

475 idea of the effect of dispersal barriers over community structuring, where communities are

476 phylogenetically similar despite their large differences in species composition, a pattern

477 reflecting the influence biogeographic barriers (Graham et al., 2009) that promote regions with a

478 set of related species with a common and isolated history, like areas of endemism (Harold \&

479 Mooi, 1994).

480 The phylogenetic overdispersion patterns we found could be related to the expectation

481 that competition influences the local trait composition of a community by promoting the filling

482 of the morphological and ecological space exploited (Wainwright \& Reilly, 1994); but it could

483 also be associated with the distribution of a lineage along a transition zone, that is, an area where

484 a mixed set of distinct biotic elements overlap (Morrone 2004). Areas found with higher

485 phylogenetic overdispersion have been recognized by other authors as areas where different 
486 biotic elements overlap, e.g parts of the Mexican Transition Zone (Sierra Madre Oriental),

487 Yucatan Peninsula and the limits of the Tehuantepec Isthmus (Morrone, 2006, 2014).

488 Contradictory to the expectations of patterns of phylogenetic structuring, our data show

489 low phylogenetic signal, so traits are less similar than expected due to phylogenetic relatedness.

490 We would have expected a strong phylogenetic signal, as closely related species of a community

491 tend to occupy similar morphological space due to common ancestry, especially in

492 phylogenetically clustered areas. Overdispersion of traits driven by competitive interactions and

493 divergent trait evolution, as well as the taxonomic and spatial scale, may have influenced the

494 results by masking phylogenetic signal patterns at different assemblages (Webb et al., 2002;

495 Cavender-Bares et al., 2006; Lawing et al., 2017). The latter seems to be the case for tyrant

496 flycatchers, as many closely related clades that supposedly have a similar distribution of traits,

497 are concentrated in the same areas of high phylogenetic structure. For example, closely related

498 and morphologically similar Empidonax and Contopus are concentrated southeastward, while

499 another set of closely related Empidonax are found concentrated westward (i.e. E. difficilis, E.

500 occidentalis, E. fulvifrons and C. cooperi, C. pertinax and C. sordidulus). On the other hand, the

501 areas that have more phylogenetically diverse communities (phylogenetic overdispersion) are

502 found in southeastern tropical region, for example the Yucatan Peninsula.

503 Another pattern revealed by our analyses was defined by the discordant response of

504 variation in body size in relation to temperature seasonality and phylogenetic relatedness (Fig.

505 4). Our results indicate that body size increases as temperature seasonality increases, but as

506 communities became more phylogenetically clustered, body size decreases, resulting in a trade-

507 off between the influences of temperature seasonality and phylogenetic relatedness over

508 variation in body size. An evolutionary trade-off suggests that the functional trait of body size is 
509 limited by the action of another trait of evolutionary and ecological importance, like the

510 relatedness of the species occurring within the community. Trade-offs can occur at different

511 hierarchical levels, and situations can even occur in which the selection on traits of individual

512 organisms is opposed to the selection on an emergent characteristic at the species level

513 (Jablonski, 2007), establishing variation patterns that cannot be fully explained by analyzing a

514 single level. Then, the variation of a characteristic of the individual like body size could be

515 opposed to the selection of a property at the species level (Diniz-Filho, 2004), like the structuring

516 of communities.

517

518 CONCLUSIONS

519 Our analyses demonstrate that the environment has an effect on morphological variation that is 520 mediated by the phylogenetic structure of communities across geography. The use of different

521 environmental variables to elucidate patterns of morphological change in lineages, with distinct

522 levels of phylogenetic signal, and varied patterns of lineage composition across space provides

523 greater explanatory power than only taking into account species richness or abundance, or simply

524 presence/absence distributional data (Olson et al., 2009; Maestri et al., 2016; Lawing et al.,

525 2017). Several authors have noticed that morphological variation is best explained by a varied set

526 of variables, given that the effect of a single climatic variable, most of the time explains variation

527 only at one scale (taxonomic or geographic, James 1970; Dial 2008; Olson et al. 2009; Martínez-

528 Monzón et al. 2017). Assessing the distribution of ecomorphological traits of organisms is the

529 best way to predict change over an environmental gradient (Olson et al. 2009; Santos et al. 2016)

530 and consequently, regression models representing variation of functional traits provide new

531 insights into elucidating the general mechanisms that relate biodiversity across environmental 
532 and geographical changes (Violle et al. 2014). A spatial visualization of the predicted response of

533 trait variation in relation to environmental factors can integrate individual and interspecific level

534 responses to evaluate the importance of morphological adaptation in the explanation of broader

535 scale processes. Finally, our results highlight that to allow a better understanding of the spatial

536 distribution patterns of morphological traits, and the processes that promote them in different

537 assemblages, it is necessary to consider the relationship of different ecomorphological traits of

538 the species in conjunction with the phylogenetic composition of the communities.

539

540 Acknowledgements. This paper constitutes a partial fulfillment of the doctoral studies at

541 Posgrado en Ciencias Biológicas of the National Autonomous University of México (UNAM) of

542 G. Cortés-Ramírez. We acknowledge the curators and collection managers of the bird collections

543 of The Field Museum, Chicago (John Bates and David Willard); Museo de Zoología "Alfonso L.

544 Herrera" de la Facultad de Ciencias, UNAM, (Fanny Rebón); “Colección Nacional de Aves” del

545 Instituto de Biología, UNAM, (Patricia Escalante). We also thank Marco Fabio Ortiz Ramírez,

546 Claudia Renata Gutierrez Arellano for the help with programs, Erick Alejandro García-Trejo for

547 valuable comments and Lynna Kiere for English proofreading. 


\section{References}

549 Adams D, and Otárola-Castillo E. 2013. geomorph: an r package for the collection and analysis $550 \quad$ of geometric morphometric shape data. Methods in Ecology and Evolution 4:393-399.

551 doi: $10.1111 / 2041-210 X .12035$

552 Adams DC. 2014. A Generalized K Statistic for Estimating Phylogenetic Signal from Shape and

553

554 Other High-Dimensional Multivariate Data. Systematic Biology 63:685-697. 10.1093/sysbio/syu030

Alvarado-Cárdenas LO, Martínez-Meyer E, Feria TP, Eguiarte LE, Hernández HM, Midgley G, and Olson ME. 2013. To converge or not to converge in environmental space: testing for similar environments between analogous succulent plants of North America and Africa. Annals of Botany 111:1125-1138. 10.1093/aob/mct078

Arbeláez-Cortés E, Milá B, and Navarro-Sigüenza AG. 2014. Multilocus analysis of intraspecific differentiation in three endemic bird species from the northern Neotropical dry forest. Molecular Phylogenetics and Evolution 70:362-377.

Berlanga H, Rodríguez-Contreras, V., Oliveras de Ita, A., Escobar, M., Rodríguez, L., Vieyra, J., Vargas, V. 2008. Red de Conocimientos sobre las Aves de México (AVESMX). CONABIO.

Blamires D, De Oliveira G, de Souza Barreto B, and Diniz-Filho JAF. 2008. Habitat use and deconstruction of richness patterns in Cerrado birds. Acta Ecologica 33:9 7 - 104.

Blomberg SP, Garland Jr T, and Ives AR. 2003. Testing for phylogenetic signal in comparative data: behavioral traits are more labile. Evolution 57:717-745.

Blomberg SP, and Garland T. 2002. Tempo and mode in evolution: phylogenetic inertia, adaptation and comparative methods. Journal of Evolutionary Biology 15:899-910. 
571 Bonetti MF, and Wiens JJ. 2014. Evolution of climatic niche specialization: a phylogenetic 572 analysis in amphibians. Proceedings of the Royal Society of London B: Biological Sciences 281:20133229.

574

575

576

577

578

579

580

581

582

583

584

585

586

587

588

589

590

591

592

Bonner JT. 2011. Why size matters: from bacteria to blue whales: Princeton University Press.

Bowlin MS, and Wikelski M. 2008. Pointed Wings, Low Wingloading and Calm Air Reduce Migratory Flight Costs in Songbirds. PLoS ONE 3:e2154.

Brown JH. 1995. Macroecology. Chicago: The University of chicago Press.

Brum FT, Kindel A, Hartz SM, and Duarte LDS. 2012. Spatial and phylogenetic structure drive frugivory in Tyrannidae birds across the range of Brazilian Araucaria forests. Oikos:no-no. 10.1111/j.1600-0706.2011.19978.x

Campbell-Tennant DJE, Gardner JL, Kearney MR, and Symonds MRE. 2015. Climate-related spatial and temporal variation in bill morphology over the past century in Australian parrots. Journal of Biogeography 42:1163-1175. doi:10.1111/jbi.12499

Cavender-Bares J, Keen A, and Miles B. 2006. Phylogenetic structure of Floridian plant communities depends on taxonomic and spatial scale. Ecology 87.

Cavender-Bares J, Kozak KH, Fine PVA, and Kembel SW. 2009. The merging of community ecology and phylogenetic biology. Ecology Letters 12:693-715. 10.1111/j.14610248.2009.01314.x

Cicero C, and Koo MS. 2012. The role of niche divergence and phenotypic adaptation in promoting lineage diversification in the Sage Sparrow (Artemisiospiza belli, Aves: Emberizidae). Biological Journal Of the Linnean Society 107:332-354. 10.1111/j.10958312.2012.01942.x 
593 Claramunt S. 2010. Discovering exceptional diversification at continental scales: the case of the 594 endemic families of neotropical suboscine passerines. Evolution 64:2004-2019.

595 Cortés-Ramírez G, Ríos-Muñoz CA, and Navarro-Sigüenza AG. 2012. Ecomorphological

596 distribution of the Tyrannides in Mexico. North American Ornithological Conference V.

$597 \quad$ Vancouver, Canada. p 359

598 Dawideit BA, Phillimore AB, Laube I, Leisler B, and Böhning-Gaese K. 2009.

599 Ecomorphological predictors of natal dispersal distances in birds. Journal of Animal

$600 \quad$ Ecology 78:388-395

601 Dehling DM, Fritz SA, Töpfer T, Päckert M, Estler P, Böhning-Gaese K, and Schleuning M.

602 2014. Functional and phylogenetic diversity and assemblage structure of frugivorous birds

603 along an elevational gradient in the tropical Andes. Ecography 37:1047-1055.

604 Deutsch CA, Tewksbury JJ, Huey RB, Sheldon KS, Ghalambor CK, Haak DC, and Martin PR.

605 2008. Impacts of climate warming on terrestrial ectotherms across latitude. Proceedings of 606 the National Academy of Sciences 105:6668-6672.

607 Dial KP, Greene E, and Irschick DJ. 2008. Allometry of behavior. Trends in Ecology \&amp; $608 \quad$ Evolution 23:394-401.

609 Diniz-Filho JAF. 2004. Macroecology and the hierarchical expansion of evolutionary theory.

$610 \quad$ Global Ecology and Biogeography 13:1-15.

611 Donoghue MJ. 2008. A phylogenetic perspective on the distribution of plant diversity.

612 Proceedings of the National Academy of Sciences 105:11549-11555.

613 Duarte LdS. 2011. Phylogenetic habitat filtering influences forest nucleation in grasslands. Oikos 614 120:208-215. 
615 Eck S, Fiebig J, Fiedler W, Heynen I, Nicolai B, Töpfer T, Van den Elzen R, Winkler R, and 616 Woog F. 2011. Measuring Birds - Vögel Vermessen.

617 Endler JA. 1977. Geographic variation, speciation, and clines: Princeton University Press. 618 Faaborg J, Holmes RT, Anders AD, Bildstein KL, Dugger KM, Gauthreaux SA, Helglund P, 619 Hobson KA, Jahn AE, Johnson DH, Latta SC, Levey DJ, Marra PP, Merkprd CL, Nol E, 620 Rothstein SI, Sherry TW, Sillet ST, Thompson FR, and Warnock N. 2010. Recent 621 622 advances in understanding migration systems of New World land birds. Ecological Monographs 80:3-48.

623 Felice RN, and Goswami A. 2017. Developmental origins of mosaic evolution in the avian 624 cranium. Proceedings of the National Academy of Sciences:201716437.

625 Fitzpatrick JW. 1980. Foraging Behavior of Neotropical Tyrant Flycatchers. Condor 82:43-57. 626 Fitzpatrick JW. 1981. Search strategies of tyrant flycatchers. Animal Behaviour 29:810-821. 627 Fitzpatrick JW. 1985. Form, Foraging Behavior, and Adaptive Radiation in the Tyrannidae. $628 \quad$ Ornithological Monographs 36:447-470.

629 Flynn DF, Mirotchnick N, Jain M, Palmer MI, and Naeem S. 2011. Functional and phylogenetic 630 diversity as predictors of biodiversity-ecosystem-function relationships. Ecology 92:1573$631 \quad 1581$.

632 Forister ML, Novotny V, Panorska AK, Baje L, Basset Y, Butterill PT, Cizek L, Coley PD, Dem 633 F, and Diniz IR. 2015. The global distribution of diet breadth in insect herbivores. 634 Proceedings of the National Academy of Sciences 112:442-447.

635 Förschler MI, and Barlein F. 2011. Morphological shifts of the external flight apparatus across 636 the range of a passerine (Northern Wheatear) with diverging migratory behaviour. PLoS 637 ONE 6:e18732 
639 García-Trejo EA, and Navarro-Sigüenza AG. 2004. Patrones biogoegráficos de la riqueza de 640 especies y el endemismo de la avifauna en el oeste de México. Acta Zoologica Mexicana $641 \quad 20: 167-185$.

642 Gatesy SM, and Dial KP. 1996. Locomotor Modules and the Evolution of Avian Flight. $643 \quad$ Evolution 50:331-340.

644 Graham CH, Parra JL, Rahbek C, and McGuire JA. 2009. Phylogenetic structure in tropical 645 hummingbird communities. Proceedings of the National Academy of Sciences 106:19673$646 \quad 19678$.

647 Graves GR. 1991. Bergmann's rule near the equator: latitudinal clines in body size of an Andean $648 \quad$ passerine bird. Proceedings of the National Academy of Sciences 88:2322-2325. 10.1073/pnas.88.6.2322

650 Greenberg R, Danner R, Olsen B, and Luther D. 2012. High summer temperature explains bill 651 size variation in salt marsh sparrows. Ecography 35:146-152. 10.1111/j.1600$652 \quad 0587.2011 .07002 . \mathrm{x}$

653 Hackett SJ, Kimball RT, Reddy S, Bowie RCK, Braun EL, Braun MJ, Chojnowski JL, Cox WA, 654 Han K-L, Harshman J, Huddleston CJ, Marks BD, Miglia KJ, Moore WS, Sheldon FH, 655 Steadman DW, Witt CC, and Yuri T. 2008. A Phylogenomic Study of Birds Reveals Their 656 Evolutionary History. Science 320:1763-1768. 10.1126/science.1157704

657 Halffter G, Moreno, C. E. 2005. Significado biológico de las diversidades alfa, beta y gamma In:

658 Halffter G, Soberón J., Koleff, P. \& Melic, A., ed. Sobre el significado biológico de las 659 diversidades alfa, beta y gamma México: CONABIO, 1-18. 
660 Hamilton TH. 1961. The Adaptive Significances of Intraspecific Trends of Variation in Wing 661 Length and Body Size Among Bird Species. Evolution 15:180-195.

662 Harold AS, and Mooi RD. 1994. Areas of endemism: definition and recognition criteria. 663 systematic Biology 43:261-266.

664 Hawkins BA, Diniz-Filho JAF, Jaramillo C, and Soeller SA. 2007. Climate, Niche 665 Conservatism, and the Global Bird Diversity Gradient. The american Naturalist 170:516$666 \quad 529$.

667 Helmus MR, Savage K, Diebel MW, Maxted JT, and Ives AR. 2007. Separating the determinants 668 of phylogenetic community structure. Ecology Letters 10:917-925.

669 Hespenheide HA. 1971. Food preference and the extent of overlap in some insectivorous birds, 670 with special reference to the Tyrannidae. Ibis 113:59-72.

671 Hijmans RJ, Cameron SE, Parra JL, Jones PG, and Jarvis A. 2005. Very high resolution 672 interpolated climate surfaces for global land areas. International Journal of Climatology $673 \quad 25: 1965-1978$.

674 IOU. 2018. IOC World Bird List, v8.1. Checklist dataset https://doi.org/10.15468/anfqn6 675 accessed via GBIF.org.

676 Jablonski D. 2007. Scale and hierarchy in macroevolution. Palaeontology 50:87-109.

677 James FC. 1970. Geographic Size Variation in Birds and Its Relationship to Climate. Ecology

678 51:365-390. doi:10.2307/1935374

679 Jarzyna MA, and Jetz W. 2016. Detecting the multiple facets of biodiversity. Trends in Ecology 680 \& Evolution 31:527-538. 
681 Jarzyna MA, Zuckerberg B, Porter WF, Finley AO, and Maurer BA. 2015. Spatial scaling of 682 temporal changes in avian communities. Global Ecology and Biogeography 24:1236-1248. $683 \quad 10.1111 /$ geb.12361

684 Jetz W, and Rahbek C. 2002. Geographic range size and determinants of avian species richness. $685 \quad$ Science 297:1548-1551.

686 Jetz W, Thomas GH, Joy JB, Hartmann K, and Mooers AO. 2012. The global diversity of birds 687 in space and time. Nature advance online publication.

688 Jones OR, Purvis A, and Quicke DLJ. 2012. Latitudinal gradients in taxonomic overdescription 689 rate affect macroecological inferences using species list data. Ecography 35:333-340.

690 10.1111/j.1600-0587.2011.06956.x

691 Kissling WD. 2007. Macroecology of avian frugivore diversity Dissertation zur Erlangung des 692 Global Ecology and Biogeography 18:150-162.

695

696

697 698 699 700 701 702 703 Grades Doktor der Naturwissenschaften. Johannes Gutenberg-Universität in Mainz.

Kissling WD, Böhning-Gaese K, and Jetz W. 2009. The global distribution of frugivory in birds.

Kivelä SM, Välimäki P, Carrasco D, Mäenpää MI, and Oksanen J. 2011. Latitudinal insect body size clines revisited: a critical evaluation of the saw-tooth model. Journal of Animal Ecology 80:1184-1195. 10.1111/j.1365-2656.2011.01864.x

Kluge J, and Kessler M. 2011. Phylogenetic diversity, trait diversity and niches: species assembly of ferns along a tropical elevational gradient. Journal of Biogeography 38:394405. 10.1111/j.1365-2699.2010.02433.x

Kobelkowsky-Vidrio T, Ríos-Muñoz CA, and Navarro-Sigüenza AG. 2014. Biodiversity and biogeography of the avifauna of the Sierra Madre Occidental, Mexico. Biodiversity and Conservation 23:2087-2105. 
704 Lawing AM, Eronen JT, Blois JL, Graham CH, and Polly PD. 2017. Community functional trait 705 composition at the continental scale: the effects of non-ecological processes. Ecography

706 40:651-663. 10.1111/ecog.01986

707

708

709

710

711

712

713

714

715

716

717

718

719

720

721

722

723

724

725

Lewin-Koh NJ, Bivand R, Pebesma E, Archer E, Baddeley A, Bibiko H, Dray S, Forrest D, Friendly M, and Giraudoux P. 2011. maptools: Tools for reading and handling spatial objects. $R$ package version 08-10, URL http://CRAN R-project org/package= maptools.

Lockwood R, Swaddle JP, and Rayner JMV. 1998. Avian wingtip shape reconsidered: wingtip shape indices and morphological adaptations to migration. Journal of Avian Biology 29:273.

Losos JB, and Miles DB. 1994. Adaptation, constraint, and the comparative method: phylogenetic issues and methods. Ecological morphology: Integrative organismal biology:60-98.

MacArthur R, and Levins R. 1967. The limiting similarity, convergence, and divergence of coexisting species. The American Naturalist 101:377-385.

Maestri R, Luza AL, Barros LD, Hartz SM, Ferrari A, Freitas TRO, and Duarte LD. 2016. Geographical variation of body size in sigmodontine rodents depends on both environment and phylogenetic composition of communities. Journal of Biogeography 43:1192-1202.

Martin JM, I MJ, and S BP. 2018. Bison body size and climate change. Ecology and Evolution 8:4564-4574. doi:10.1002/ece3.4019

Martínez-Monzón A, Blain H-A, Cuenca-Bescós G, and Rodríguez MÁ. 2017. Climate and amphibian body size: a new perspective gained from the fossil record. Ecography:n/a-n/a. 10.1111/ecog.03440 
726 Mazel F, Pennell M, Cadotte M, Diaz S, Dalla Riva G, Grenyer R, Leprieur F, Mooers A,

727 Mouillot D, Tucker C, and Pearse W. 2018. Is phylogenetic diversity a surrogate for

728 functional diversity across clades and space? bioRxiv. 10.1101/243923

729 Mazer SJ, and Wheelwright NT. 1993. Fruit size and shape: Allometry at different taxonomic

$730 \quad$ levels in bird-dispersed plants. Evolutionary Ecology 7:556-575. 10.1007/bf01237821

731 McNab BK. 1971. On the Ecological Significance of Bergmann's Rule. Ecology 52:845-854.

732 $10.2307 / 1936032$

733

734

735

736

737

738

739

740

741

742

743

744

745

746

747 748

Miles DB, and Ricklefs RE. 1984. The Correlation Between Ecology and Morphology in Deciduous Forest Passerine Birds. Ecology 65:1629-1640.

Militino AF. 2010. Mixed Effects Models and Extensions in Ecology with R. Journal of the Royal Statistical Society: Series A (Statistics in Society) 173:938-939.

Miller E, Zanne A, and Ricklefs R. 2013. Niche conservatism constrains Australian honeyeater assemblages in stressful environments. Ecology Letters 16:1186-1194.

Moles AT, Wallis IR, Foley WJ, Warton DI, Stegen JC, Bisigato AJ, Cella-Pizarro L, Clark CJ, Cohen PS, and Cornwell WK. 2011. Putting plant resistance traits on the map: a test of the idea that plants are better defended at lower latitudes. New Phytologist 191:777-788.

Morrone JJ. 2004. Panbiogeografía, componentes bióticos y zonas de transición. Revista Brasileira de Entomologia 48:149-162.

Morrone JJ. 2006. Biogeographic areas and transition zones of latin america and the Caribbean Islands basen on panbiogeographic and cladistic analyses of the Entomofauna. Annual Review of Entomolgoy 51:467-494.

Morrone JJ. 2014. Biogeographical regionalisation of the Neotropical region. Zootaxa 3782:1110. 
749 Navarro A, Garza-Torres H, De Aquino SL, Rojas-Soto O, and Sánchez-González L. 2004.

750 Patrones biogeográficos de la avifauna. In: Luna I, Morrone JJ, and Espinosa D, eds.

751 Biodiversidad de la Sierra Madre Oriental. Mexico: Las Prensas de Ciencias, UNAM,

$752 \quad$ México, DF, 439-467.

753 O'Donnel MS, and Ignizio DA. 2012. Bioclimatic predictors for supporting ecological

754 applications in the conterminous United States. US Geological Survey.

755 Ohlson J, Fjeldså J, and Ericson P. 2008. Tyrant flycatchers coming out in the open: phylogeny

756 and ecological radiation of Tyrannidae (Aves: Passeriformes). Zoologica Scripta 37:315-

$757 \quad 335$.

758 Olguín-Monroy HC, Gutiérrez-Blando C, Ríos-Muñoz CA, León-Paniagua L, and Navarro-

759 Sigüenza AG. 2013. Regionalización biogeográfica de la mastofauna de los bosques

760 tropicales perennifolios de Mesoamérica. Revista de Biología Tropical 61:937-969.

761 Olson VA, Davies RG, Orme DL, Thomas GH, Meiri S, Blackburn TM, Gaston KJ, Owens IPF, 762 and Bennet PM. 2009. Global biogeography and ecology of body size in birds. Ecology

763 Letters 12:249-259.

764

765

766

767

768

769

770

771

Peters RH, and Peters RH. 1986. The ecological implications of body size: Cambridge University Press.

Phillips AG, Töpfer T, Rahbek C, Böhning-Gaese K, and Fritz SA. 2018. Effects of phylogeny and geography on ecomorphological traits in passerine bird clades. Journal of Biogeography 00:1-11. https://doi.org/10.1111/jbi.13383

Pol M, Bailey LD, McLean N, Rijsdijk L, Lawson CR, and Brouwer L. 2016. Identifying the best climatic predictors in ecology and evolution. Methods in Ecology and Evolution $7: 1246-1257$. 
772 Pontarotti P. 2010. Evolutionary Biology. Concepts, Molecular and Morphological Evolution:

$773 \quad$ Springer.

774 R-Core-Team. 2017. R: A language and environment for statistical computing.

775 Ricklefs RE, and Miles DB. 1994. Ecological and evolutionary inferences from morphology: an

776 ecological perspective. Ecological morphology: integrative organismal biology University

777 of Chicago Press, Chicago 101:13-41.

778 Ricklefs RE. 2012. Species richness and morphological diversity of passerine birds. Proceedings

779 of the National Academy of Sciences. 10.1073/pnas.1212079109

780 Ridgely RS, T. F. Allnutt, T. Brooks, D. K. McNicol, D. W. Mehlman, B. E. Young, and J. R.

781 Zook. 2005. Digital Distribution Maps of the Birds of the Western Hemisphere, version

782 2.1. NatureServe, Arlington, Virginia, USA.

783 Ridgely RS, and Tudor G. 2009. Field guide to the songbirds of South America: the passerines:

$784 \quad$ University of Texas Press.

785 Ríos-Muñoz CA, and Navarro-Sigüenza AG. 2012. Patterns of species richness and

786 biogeographic regionalization of the avifaunas of the seasonally dry tropical forest in

787 Mesoamerica. Studies on Neotropical Fauna and Environment 47:171-182.

$788 \quad 10.1080 / 01650521.2012 .734175$

789 Rodríguez D, and Ojeda RA. 2014. Scaling functional diversity of small mammals in desert $790 \quad$ systems. Journal of Zoology 293:262-270.

791 Ruggiero A, and Werenkraut V. 2007. One-dimensional analyses of Rapoport's rule reviewed

792 through meta-analysis. Global Ecology and Biogeography 16:401-414. 
793 Saito VS, Cianciaruso MV, Siqueira T, Fonseca-Gessner AA, and Pavoine S. 2016. Phylogenies

794 and traits provide distinct insights about the historical and contemporary assembly of

795 aquatic insect communities. Ecology and Evolution 6:2925-2937.

796 Salewski V, and Watt C. 2017. Bergmann's rule: a biophysiological rule examined in birds.

797 Oikos 126(2). 10.1111/oik.03698

798 Santos AMC, Cianciaruso MV, and De Marco P. 2016. Global patterns of functional diversity 799 and assemblage structure of island parasitoid faunas. Global Ecology and Biogeography

$800 \quad 25: 869-879.10 .1111 /$ geb. 12340

801 Schmidt-Nielsen K. 1984. Scaling: why is animal size so important?: Cambridge University 802 Press.

803 Schneider FD, Morsdorf F, Schmid B, Petchey OL, Hueni A, Schimel DS, and Schaepman ME.

804 2017. Mapping functional diversity from remotely sensed morphological and physiological

805 forest traits. Nature Communications 8:1441. 10.1038/s41467-017-01530-3

806 Seeholzer G, Claramunt S, and Brumfield, R. 2017. Niche evolution and diversification in a

807 Neotropical radiation of birds (Aves: Furnariidae). Evolution 71:702-715.

808 Seoane J, Bustamante J, and Diaz-Delgado R. 2004. Competing roles for landscape, vegetation,

809 topography and climate in predictive models of bird distribution. Ecological Modelling

$810 \quad 171: 209-222$.

811 Sherry TW. 1984. Comparative dietary ecology of sympatric, insectivorous Neotropical

812 flycatchers (Tyrannidae). Ecological Monographs 54:313-338.

813 Sobral FL, and Cianciaruso MV. 2016. Functional and phylogenetic structure of forest and 814 savanna bird assemblages across spatial scales. Ecography 39:533-541. 
815 Swaddle JP, and Lockwood R. 1998. Morphological adaptations to predation risk in passerines.

$816 \quad$ Journal of Avian Biology 29:172.

817 Symonds M, and GJ Tattersall. 2010. Geographical Variation in Bill Size across Bird Species

818 Provides Evidence for Allen's Rule. The american Naturalist 176:188-197.

$819 \quad 10.1086 / 653666$

820 Team RC, Pinheiro J, Bates D, DebRoy S, and Sarkar D. 2013. nlme: Linear and Nonlinear $821 \quad$ Mixed Effects Models. R package version 3.1-113.

822 Tedersoo L, Bahram M, Toots M, Diedhiou AG, Henkel TW, Kjøller R, Morris MH, Nara K, 823 Nouhra E, and Peay KG. 2012. Towards global patterns in the diversity and community 824 structure of ectomycorrhizal fungi. Molecular Ecology 21:4160-4170.

825 Tello JG, Moyle RG, Marchese DJ, and Cracraft J. 2009. Phylogeny and phylogenetic 826 classification of the tyrant flycatchers, cotingas, manakins, and their allies (Aves: 827 Tyrannides). Cladistics 25:1-39.

828 Tsirogiannis C, and Sandel B. 2016. PhyloMeasures: a package for computing phylogenetic 829 biodiversity measures and their statistical moments. Ecography 39:709-714.

$830 \quad$ doi: $10.1111 /$ ecog.01814

831 Violle C, Reich PB, Pacala SW, Enquist BJ, and Kattge J. 2014. The emergence and promise of 832 functional biogeography. Proceedings of the National Academy of Sciences 111:13690833 13696.

834 Wainwright PC, and Reilly SM. 1994. Ecological morphology: integrative organismal biology: $835 \quad$ University of Chicago Press.

836 Webb CO, Ackerly DD, McPeek MA, and Donoghue MJ. 2002. Phylogenies and community 837 ecology. Annual Review of Ecology and Systematics 33:475-505. 
838 Wiens JJ, and Graham CH. 2005. Niche Conservatism: Integrating Evolution, Ecology, and 839 Conservation Biology. Annual Review of Ecology, Evolution, and Systematics 36:519-539.

840 Winkler H, and Leisler B. 1992. On the ecomorphology of migrants. Ibis 134 suppl. 1: 21-28

841 Xu J, Chen Y, Zhang L, Chai Y, Wang M, Guo Y, Li T, and Yue M. 2017. Using phylogeny and 842 functional traits for assessing community assembly along environmental gradients: A

843 deterministic process driven by elevation. Ecology and Evolution 7:5056-5069.

$844 \quad 10.1002 /$ ece 3.3068

845 Zellweger F, Baltensweiler A, Ginzler C, Roth T, Braunisch V, Bugmann H, and Bollmann K. 846 2016. Environmental predictors of species richness in forest landscapes: abiotic factors 847 versus vegetation structure. Journal of Biogeography 43:1080-1090. 10.1111/jbi.12696

848 Zuur AF, Ieno EN, Walker NJ, Saveliev AA, and Smith GM. 2009. Mixed effects modelling for 849 nested data. Mixed effects models and extensions in ecology with R: Springer, 101-142.

850 


\section{Table $\mathbf{1}$ (on next page)}

Bioclimatic variables used to construct the climatic indexes. 


\begin{tabular}{|c|c|c|c|}
\hline $\begin{array}{c}\text { Temperature mean } \\
\text { variation index }\end{array}$ & $\begin{array}{l}\text { Temperature range } \\
\text { index (seasonality) }\end{array}$ & $\begin{array}{c}\text { Variation of } \\
\text { precipitation in humid } \\
\text { season }\end{array}$ & $\begin{array}{l}\text { Variation of } \\
\text { precipitation in the dry } \\
\text { season }\end{array}$ \\
\hline $\begin{array}{l}\text { BIO1 = Annual Mean } \\
\text { Temperature } \\
\text { BIO5 = Max } \\
\text { Temperature of Warmest } \\
\text { Month } \\
\text { BIO6 = Min } \\
\text { Temperature of Coldest } \\
\text { Month } \\
\text { BIO8 = Mean } \\
\text { Temperature of Wettest } \\
\text { Quarter } \\
\text { BIO9 = Mean } \\
\text { Temperature of Driest } \\
\text { Quarter } \\
\text { BIO10 = Mean } \\
\text { Temperature of Warmest } \\
\text { Quarter } \\
\text { BIO11 = Mean } \\
\text { Temperature of Coldest } \\
\text { Ouarter }\end{array}$ & $\begin{array}{l}\text { BIO4 = Temperature } \\
\text { Seasonality (standard } \\
\text { deviation *100) } \\
\text { BIO7 = Temperature } \\
\text { Annual Range (BIO5- } \\
\text { BIO6) } \\
\text { BIO2 = Mean Diurnal } \\
\text { Range (Mean of monthly } \\
\text { (max temp - min temp)) } \\
\text { BIO3 = Isothermality } \\
(\text { BIO2/BIO7) }(* 100)\end{array}$ & $\begin{array}{l}\text { BIO13 = Precipitation of } \\
\text { Wettest Month } \\
\text { BIO16 = Precipitation of } \\
\text { Wettest Quarter } \\
\text { BIO12 = Annual } \\
\text { Precipitation } \\
\text { BIO18 = Precipitation of } \\
\text { Warmest Quarter }\end{array}$ & $\begin{array}{l}\text { BIO14 = Precipitation of } \\
\text { Driest Month } \\
\text { BIO15 = Precipitation } \\
\text { Seasonality (Coefficient } \\
\text { of Variation) } \\
\text { BIO17 = Precipitation of } \\
\text { Driest Quarter } \\
\text { BIO19 = Precipitation of } \\
\text { Coldest Quarter }\end{array}$ \\
\hline
\end{tabular}

All bioclimatic variables taken from Worldclim 1.4 project (http://www.worldclim.org, Hijmans et al. 2005) 


\section{Table 2 (on next page)}

Variables used as fixed terms, interactions and random effects in the regression models for the Mexican tyrant flycatcher. 
1

Morphological variables

Response variables

\section{Body mass}

(as size proxy)

Wing length

Bill variation
Body size is a major influential variable that explains most of the morphological and trait variation within an individual and a species. It is strongly related to their ecology, and also imposes physical constraints to other morphological traits of birds. Body size can predict from the proportion of body parts to the distribution patterns of a species. Its variation has been related to variation in climate and other environmental and phylogenetic factors.

Wing is considered a major eco-evolutionary module of the birds, that is, a body part identified as an anatomical subregion of the musculoskeletal system that is highly integrated and act as functional unit during locomotion. Wing is related to habitat exploitation and locomotion (bird flight), because of that, wing variation is very physically constrained. For tyrant flycatchers, wing is usually related to the type of habitat that the individual lives in and exploits, as they use a special flights called sallies to catch their prey. Wing shape directly influences evasive movements against predators. Also, the shape and length of the wing are important factors as they directly influence the dispersal ability of birds. Several species of tyrant flycatchers are migratory, so wing length is an important aspect that is directly related to migratory movements.

Bill is another major module of the birds, that is, a body part identified as an anatomical subregion of the head that is highly integrated and acts as functional unit during specific processes of the individual, like feeding or communication. For this reason, bill is related to many features of the ecology of the bird, and varies and responds to environmental and evolutionary factors semi-autonomously from other body parts. For tyrant flycatchers, it is most related to their diet breadth and insectivorous feeding habits.
Schmidt-Nielsen (1984); Peters \& Peters (1986); Olson et al. (2009);

Bonner (2011); Salewski \& Watt (2016)

Hamilton (1961); Fitzpatrick (1980); Fitzpatrick (1981); Fitzpatrick (1985); Miles \& Ricklefs (1984); Winkler \&

Leisler (1992), Gatesy \& Dial (1996), Swaddle \& Lockwood (1998); Bowlin \& Wikelski (2008); Dawideit et al. 2009; Förschler \& Barlein 2011

Fitzpatrick (1980); Fitzpatrick (1985); Symonds \& Tattersall (2010); Greenberg et al. (2012); Felice \& Goswami (2017)

\section{Predictor variables}

Fixed terms

\section{Climatic variables \\ Temperature means \\ Temperature range \\ Variation of precipitation in \\ humid season \\ Variation of precipitation in \\ the dry season}

Climatic gradients are part of the environment in which a species occurs. Variables of temperature and precipitation have been related to many functions of organisms and species, as they affect the variation of many morphological traits. For instance body size, distribution range, habitat and diet breadth (niche breadth), reproductive traits, trophic level, and others. In particular, for tyrant flycatchers, temperature means and range variation could define the suitable areas for occupation and habitat distribution. They also are supposedly major drivers of morphological trait variation. Precipitation seasonality may be related to the distribution of food, as insect abundance within forests and other habitats is correlated with the humid season. Body size and appendage size may be related to climate gradients following the Bergmann's and Allen's rules, respectively, as temperature decrease, body size increases but appendage sizes decrease.
Diniz-Filho (2004); Zellweger et al. (2006); O'Donnel \& Ignizio (2012), Symonds \& Tattersall (2010);

Salewski \& Watt (2016) 


$\begin{array}{ll}\text { Altitude } & \text { There is evidence that climatic patterns of precipitation and temperature are affected by altitude. For } \\ \text { Topographic setting } & \text { instance, temperature drops with altitude and precipitation patterns differs with the topographic } \\ \text { (northness and eastness) } & \text { orientation within a mountainous area (hillshade effect). }\end{array}$

(northness and eastness)

orientation within a mountainous area (hillshade effect).

\section{Phylogenetic structure}

Communities are assembled at the local level from regional pools of species, by means of competition and other biotic interactions, and also by the local dispersion or clustering of functional traits. But at the regional scale, the sorting of species, in relation to functional traits can be related to large-scale environmental and climatic gradients. The sorting of individuals at both scales is the result of the combination of the patterns and processes occurring at different scales, and includes a historical component by which the community (or assemblage) is constructed, that is the phylogenetic relatedness of the members of the community. Closely related species can coexist based on the distribution of their functional traits, so the trait composition of the community is predictable because of the sorting of individuals and the history of the community. Then, the phylogenetic structure of a community can potentially explain the distribution of the trait at the community or assemblage scale.
MacArthur \& Levins (1967); Webb et al. (2002); Cavender-Bares et al. (2009); Lawing et al. (2017)

\section{Interaction terms}

Altitude x Climatic variables (one interaction with altitude per each climatic index)
As there is clear evidence of the relationship between climate and altitude, we considered that the interaction between the two types of variables) must be considered in the model as a term that might explain morphological variation.

Seoane et al. (2004)

\section{Predictor variables}

\section{Random effect}

Species of a subfamily at an assemblage influenced by the phylogenetic structure of the communities
Individual's morphological traits are likely to resemble the morphology of another individual of the same species more closely, simply because they belong to the same phylogenetic group (their shared common ancestry). Measures from individuals of the same species are expected to be correlated; this nested structure potentially violates the statistical assumptions of independence among data, so it has to be considered in the analysis.
Blomberg \& Garl\& (2002); Blomberg et al. (2003);

Zuur et al. (2009)

\section{Variance structure}

Phylogenetic membership of species
Different species groups may have different responses to the fixed terms, thus morphological variables show different dispersion of the data simply because they belong to different groups.
Blomberg \& Garl\& (2002); Blomberg et al. (2003);

Zuur et al. (2009) 


\section{Table 3 (on next page)}

Best-fitting models for each morphological trait using mixed-effects model regression.

$\log \mathrm{LIK}=$ Maximum Likelihood; AIC = Akaike's information criterion; BIC= Bayesian Information Criterion. 


\begin{tabular}{|c|c|c|c|c|c|c|c|c|}
\hline & $\begin{array}{l}\text { Morphological } \\
\text { variable }\end{array}$ & AIC & BIC & $\log \mathrm{LIK}$ & Model structure & Intercept & Slope & $p$-value \\
\hline \multicolumn{9}{|l|}{$\begin{array}{l}\text { Regional } \\
\text { level }\end{array}$} \\
\hline & Body size & -167.095 & -144.515 & 90.547 & logMass $\sim$ Temperature seasonality & 1.11 & 0.42 & $<0.001$ \\
\hline & Bill & 490.442 & 503.409 & -241.221 & logMass $\sim$ Temperature seasonality & -0.94 & 0.65 & $<0.05$ \\
\hline & Wing & -431.851 & -402.917 & 224.925 & $\log$ Mass $\sim$ Temperature seasonality & 1.81 & 0.091 & $<0.001$ \\
\hline \multicolumn{9}{|l|}{$\begin{array}{c}\text { Assemblage } \\
\text { I }\end{array}$} \\
\hline & Body size & -157.429 & -128.495 & 87.714 & $\begin{array}{l}\text { logMass } \sim \text { Temperature } \\
\text { relatednessl }\end{array}$ & 1.12 & $0.56,-0.35$ & $<0.001$ \\
\hline & Bill & 491.238 & 504.205 & -241.619 & $\begin{array}{l}\text { logMass } \sim \text { Temperature seasonality }+ \text { phylogenetic } \\
\text { relatedness }\end{array}$ & -0.94 & $0.043,0.03$ & $<0.05$ \\
\hline & Wing & -460.550 & -444.368 & 235.275 & $\begin{array}{l}\text { logMass } \sim \text { Temperature seasonality }+ \text { phylogenetic } \\
\text { relatedness }\end{array}$ & 1.81 & $-0.002,-0.014$ & 0.45 \\
\hline \multicolumn{9}{|l|}{$\begin{array}{c}\text { Assemblage } \\
\text { II }\end{array}$} \\
\hline & Body size & -178.785 & -162.602 & 94.392 & $\begin{array}{l}\text { logMass } \sim \text { Temperature seasonality }+ \text { phylogenetic } \\
\text { relatedness }\end{array}$ & 1.11 & $0.65,0.60$ & $<0.001$ \\
\hline & Bill & 513.291 & 542.226 & -247.645 & $\begin{array}{l}\text { logMass } \sim \text { Temperature seasonality }+ \text { phylogenetic } \\
\text { relatedness }\end{array}$ & -0.94 & $0.034,0.029$ & 0.06 \\
\hline & Wing & -475.085 & -462.118 & 241.542 & $\begin{array}{l}\operatorname{logMass} \sim \text { Temperature mean variation }+ \text { phylogenetic } \\
\text { relatedness }\end{array}$ & 1.36 & $-0.004,-0.013$ & 0.141 \\
\hline
\end{tabular}

1 Assemblage I: Lowland tropical forests. Assemblage II: Highlands above 1500 masl and other types of vegetation. Regional level the combination of

2 assemblages I and II. 


\section{Figure 1}

Geographical limits of the three delimited tyrant flycatchers datasets on the basis of the species distributed within Mexico.

Areas in green represent the distribution of the lowland tropical dry and humid forests (Assemblage I) and in brown the forests above 1500m (highland forests) or other types of vegetation (Assemblage II), the combination of both represents the regional level. Modified from Ríos-Muñoz \& Navarro-Sigüenza (2012) and Olguín-Monroy et al. (2013).

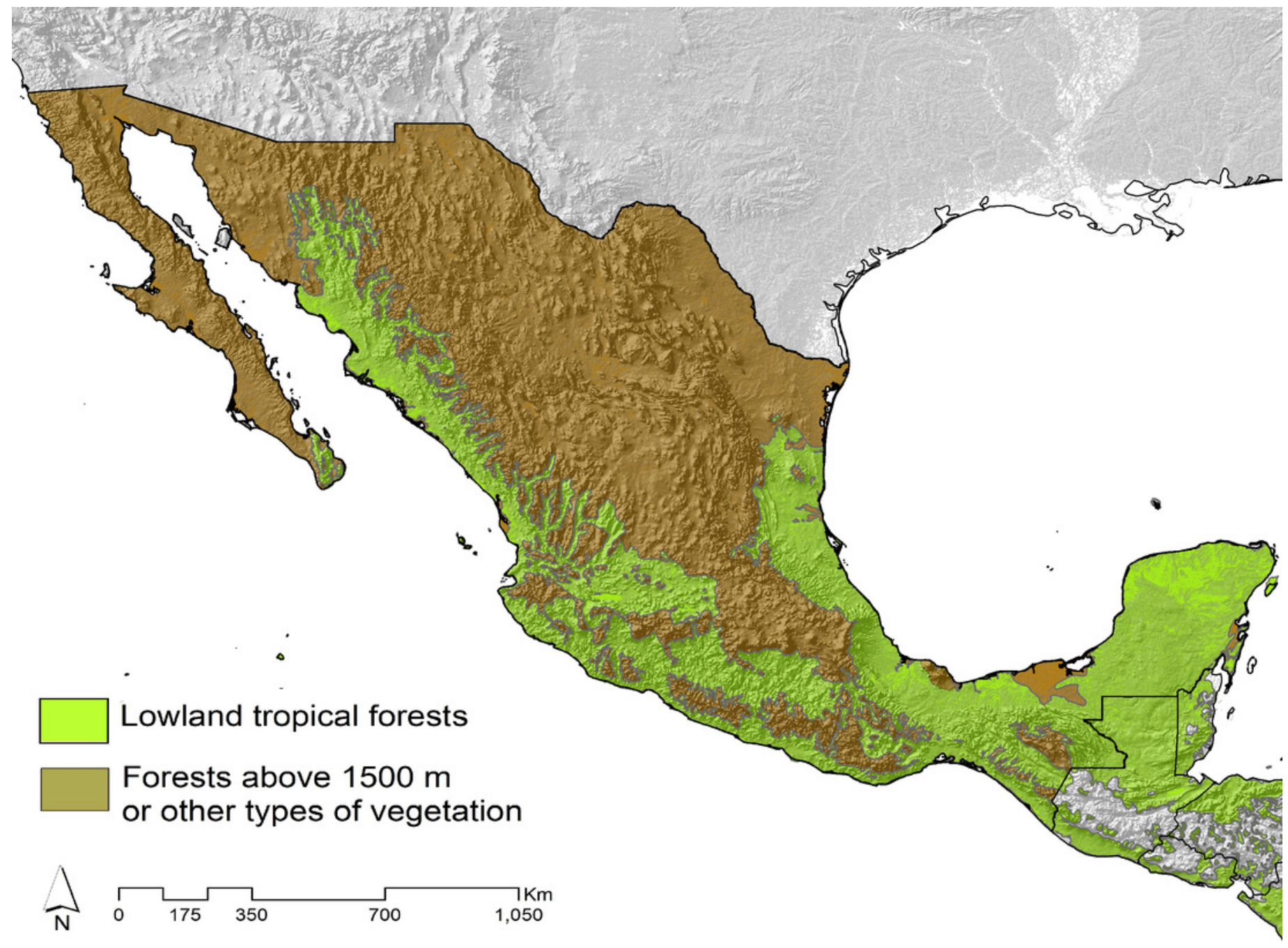


Figure 2

Geographical patterns of phylogenetic signal.

(A) Phylogenetic signal at localities of the lowland forests. (B) Phylogenetic signal at localities of the highland forests or other types of vegetation. 

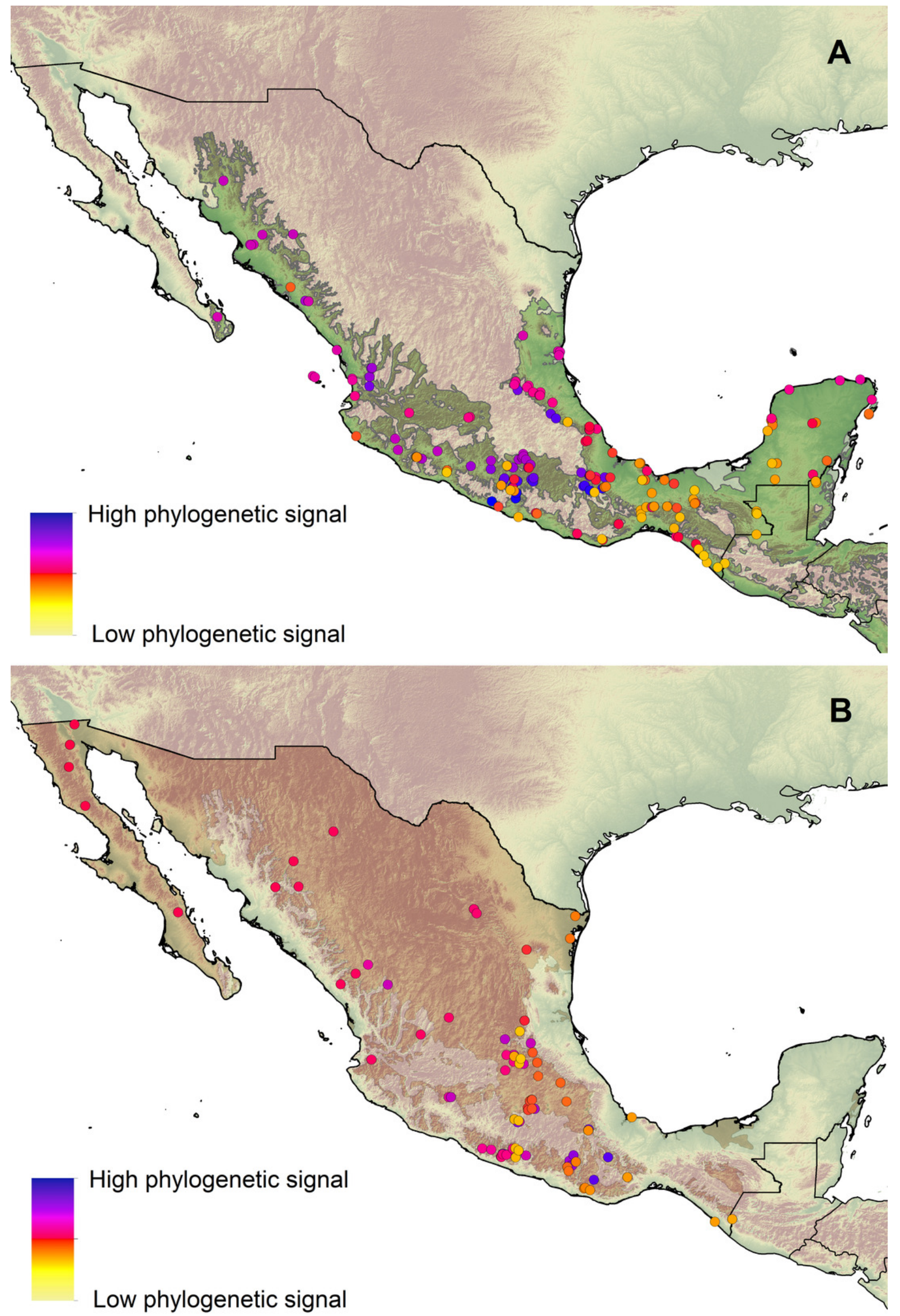


\section{Figure 3}

Spatial distribution of morphological variation of body size, bill size and wing length fitted for the regional level by temperature seasonality.

(A) Predicted spatial distribution of morphological variation. (B) Scatterplot diagram and regression lines for the predicted response of body size, bill and wing to the increase in Temperature seasonality

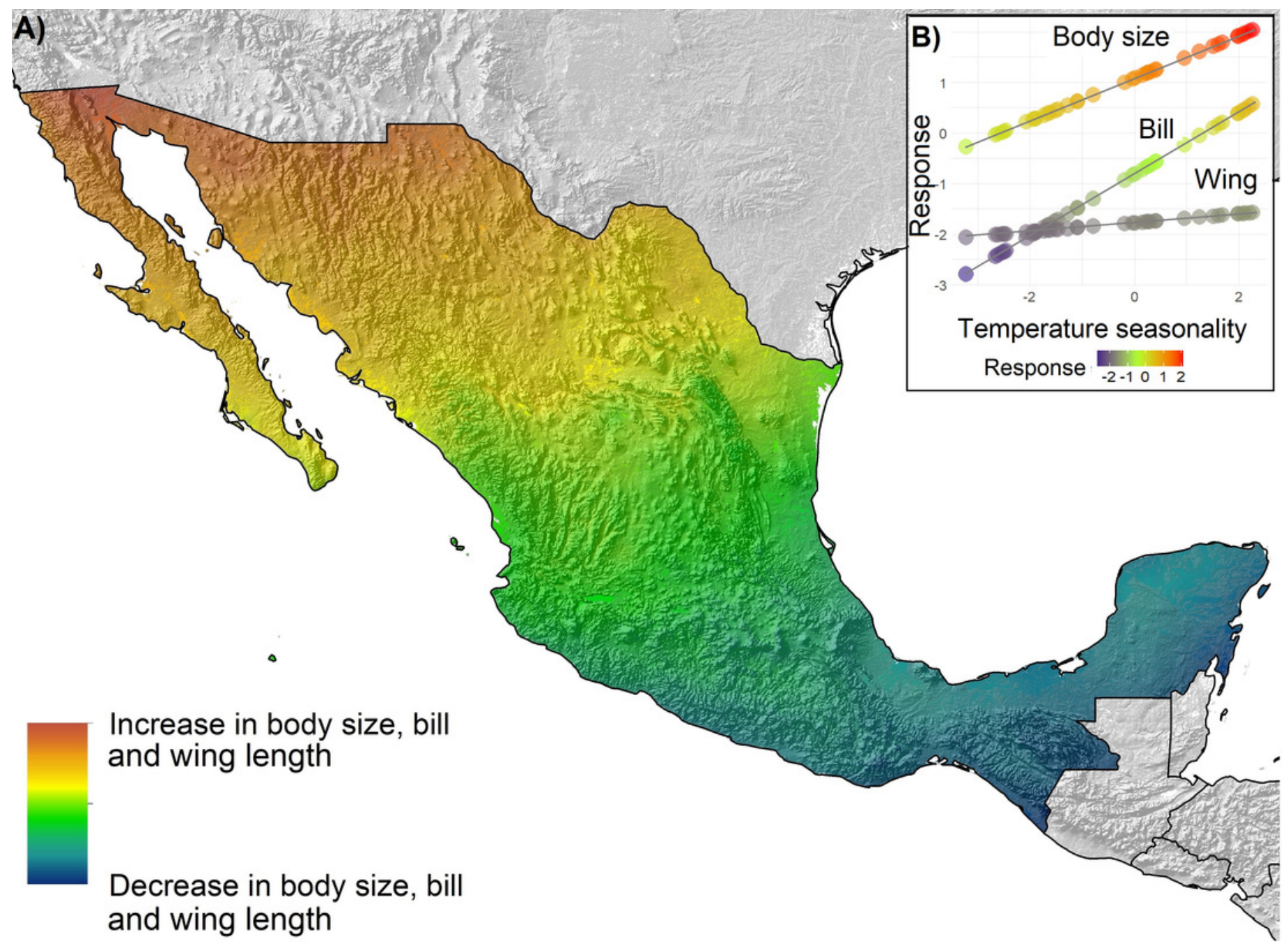




\section{Figure 4}

Spatial distribution of morphological variation of body size and bill fitted for Assemblage I by temperature seasonality

(A) Predicted spatial distribution of morphological variation. (B) Scatterplot diagram and regression lines for the predicted response of body size and bill to the increase in temperature seasonality. (C) Scatterplot diagram and regression lines for the predicted response of body size and bill to the increase in phylogenetic clustering.

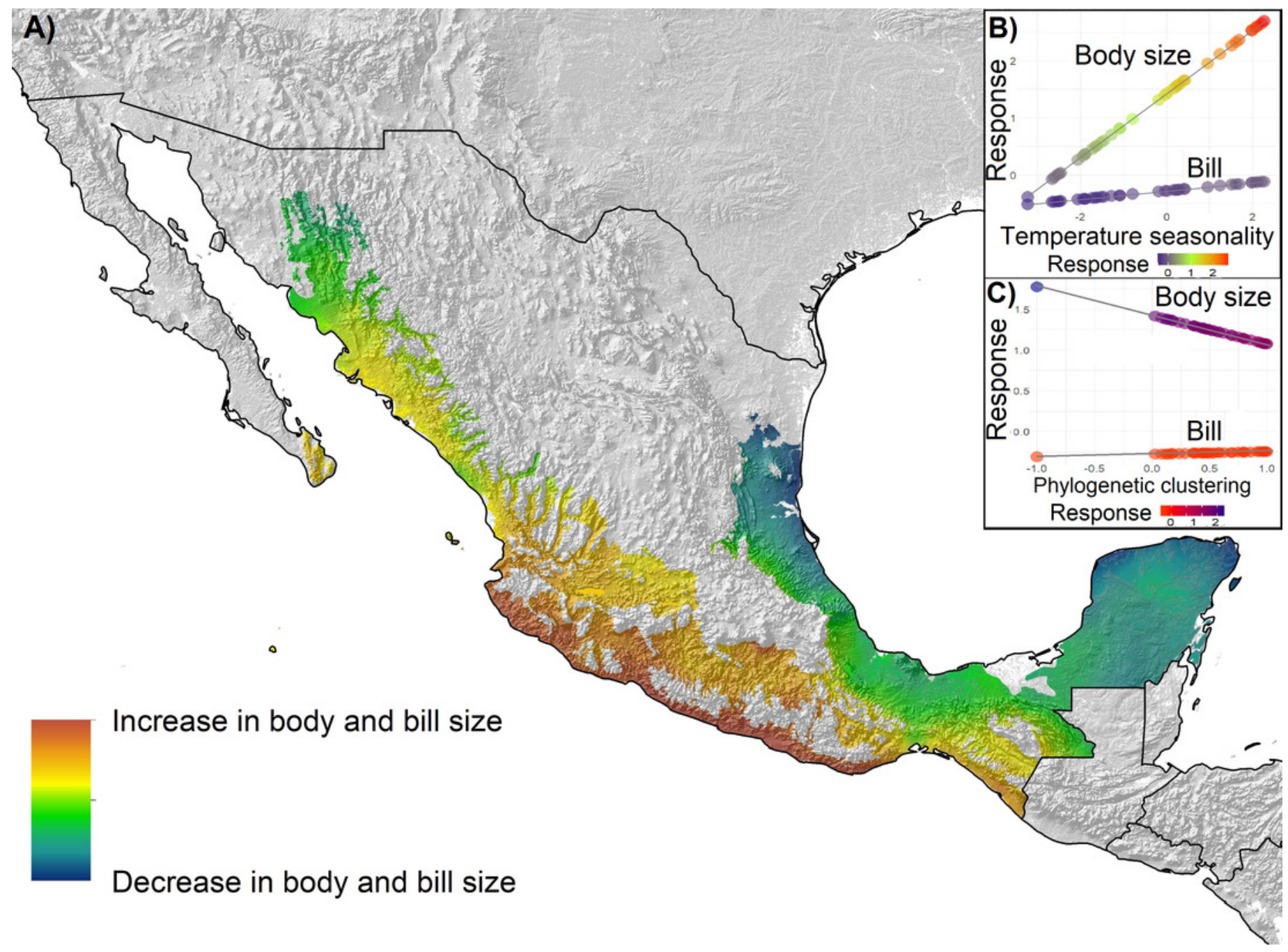




\section{Figure 5}

Spatial distribution of morphological variation of of body size fitted for Assemblage II by temperature seasonality.

(A) Predicted spatial distribution of morphological variation. (B) Scatterplot diagram and regression lines for the predicted response of body size to the increase in temperature seasonality. (C) Scatterplot diagram and regression lines for the predicted response of body size to the increase in phylogenetic clustering.

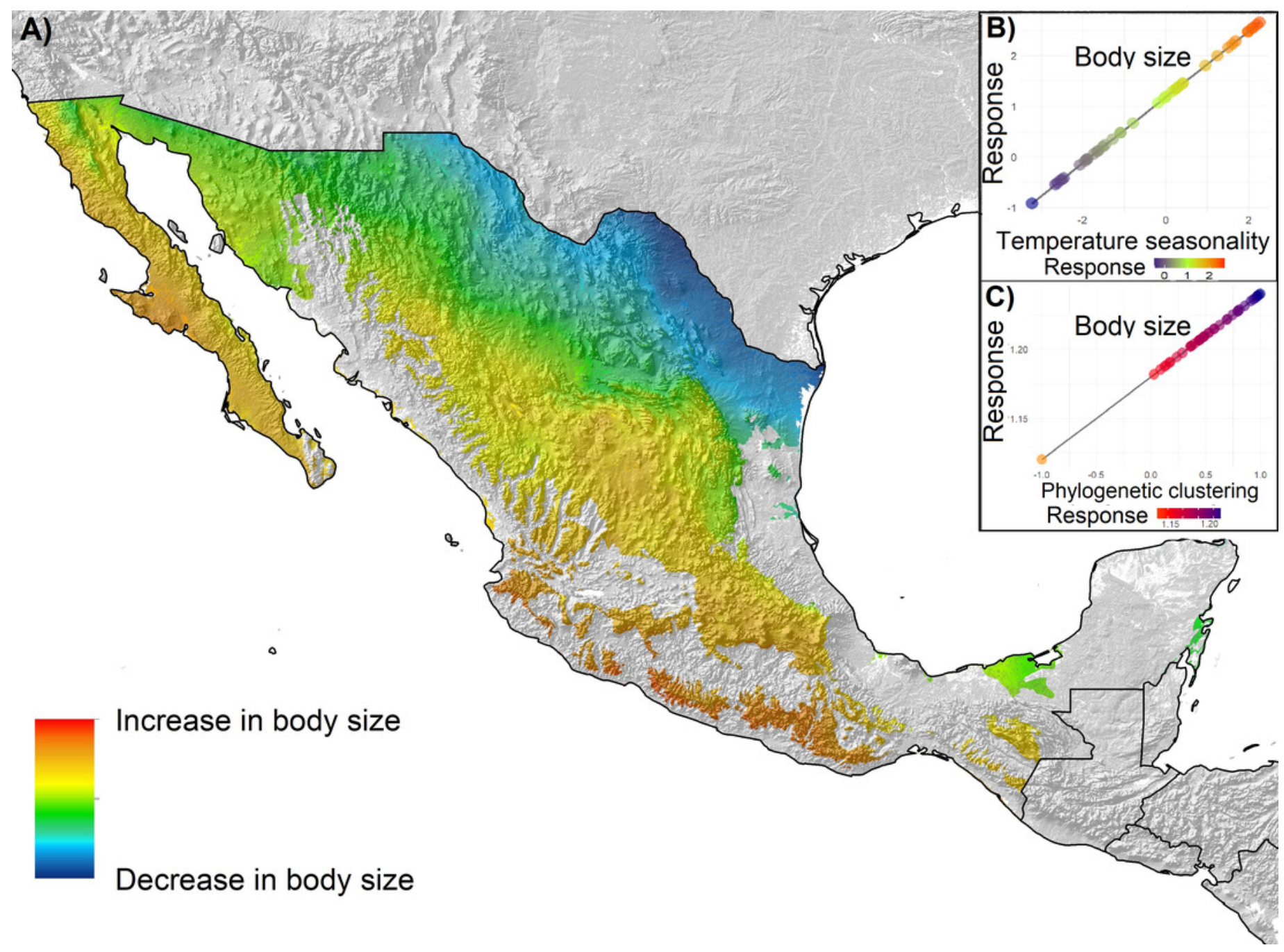

